Article

\title{
Seasonal Growth of Zygophyllum dumosum Boiss.: Summer Dormancy Is Associated with Loss of the Permissive Epigenetic Marker Dimethyl H3K4 and Extensive Reduction in Proteins Involved in Basic Cell Functions
}

\author{
Janardan Khadka + (1), Narendra S. Yadav +(D), Gila Granot and Gideon Grafi * \\ French Associates Institute for Agriculture and Biotechnology of Drylands, Jacob Blaustein Institutes for Desert \\ Research, Ben-Gurion University of the Negev, Midreshet Ben-Gurion 84990, Israel; \\ janak_khd@hotmail.com (J.K.); nsyadava2004@gmail.com (N.S.Y.); granotg@exchange.bgu.ac.il (G.G.) \\ * Corespondence: ggrafi@bgu.ac.il; Tel.: +972-8-6563479 \\ + These authors contributed equal to this work.
}

Received: 3 June 2018; Accepted: 4 July 2018; Published: 15 July 2018

\begin{abstract}
Plants thriving in desert environments are suitable for studying mechanisms for plant survival under extreme seasonal climate variation. We studied epigenetic mechanisms underlying seasonal growth cycles in the desert plant Zygophyllum dumosum Boiss., which was previously shown to be deficient in repressive markers of di-methyl and tri-methyl H3K9 and their association with factors regulating basic cell functions. We showed a contingent association between rainfall and seasonal growth and the epigenetic marker of dimethyl H3K4, which disappears upon entry into the dry season and the acquisition of a dormant state. DNA methylation is not affected by a lack of H3K9 di-methyl and tri-methyl. Changes in methylation can occur between the wet and dry season. Proteome analysis of acid soluble fractions revealed an extensive reduction in ribosomal proteins and in proteins involved in chloroplasts and mitochondrial activities during the dry seasons concomitantly with up-regulation of molecular chaperone HSPs. Our results highlight mechanisms underlying Z. dumosum adaptation to seasonal climate variation. Particularly, summer dormancy is associated with a loss of the permissive epigenetic marker dimethyl H3K4, which might facilitate genome compaction concomitantly with a significant reduction in proteins involved in basic cell functions. HSP chaperones might safeguard the integrity of cell components.
\end{abstract}

Keywords: epigenetics; H3K9 methylation; H3K4 methylation; DNA methylation; seasonal climate change; summer dormancy; heat shock proteins; ribosomal proteins; Zygophyllum dumosum Boiss

\section{Introduction}

In nearly all agricultural regions, abiotic stresses such as drought, salinity, and temperature extremes reduce average yields for most major crop plants by more than $50 \%$, which presents a huge impediment to feeding an ever-growing world population [1]. With the expected changes in the global climate, environmental stresses are likely to increase in severity. This emphasizes the need for better understanding of the biological basis for abiotic stress tolerance in plants. Conceivably, plants flourishing in harsh desert environments might possess novel mechanisms for stress tolerance and are most suited for studying biochemical and molecular mechanisms for plant survival under variable seasonal climate conditions. The desert plant Zygophyllum dumosum Boiss. (bushy bean caper), which is a Saharo-Arabian phytogeographical element, inhabits desert regions in Israel (Judea desert and the central Negev) and Egypt (central Sinai) [2]. It is adapted to a variable, desert environment through 
multiple morphological and molecular mechanisms that act together to bring about the survival of the plant to a combination of stresses prevailing in the desert ecosystem. On entry into the summer, $Z$. dumosum shed its leaflets leaving the thick, wax-covered petioles alive and capable of survival for two full growing seasons [3]. During the summer, Z. dumosum in the field enters true dormancy, which is characterized by cessation of cambial activity and by the failure to reactivate this activity and resume growth even after an ample supply of water [4]. Dormancy in the remaining petioles is facilitated by a significant reduction in nuclear size/volume resulting from genome compaction [3]. Therefore, summer dormancy likely provides a major strategy for 'drought survival' during the dry season [5,6]. Previous studies showed that Z. dumosum as well as other Zygophyllaceae species, which usually inhabit dry and semidry regions worldwide, do not possess the repressive epigenetic markers of di-methyl and tri-methyl lysine 9 of histone H3 (H3K9) but do contain mono-methyl H3K9 [3,7]. Histone methylation is specific and is catalyzed by various enzymes that add a methyl group to a specific lysine or arginine residue. For example, SET domain-containing histone methyltransferases such as KRYPTONITE/SUVH4, SUVH5, and SUVH6 in A. thaliana are enzymes that specifically methylate histone $\mathrm{H} 3$ at lysine 9 [8], which generates a binding site for $\mathrm{CHROMO}$-containing proteins such as CHROMOMETHYLASE3 (CMT3) [9]. This is an enzyme that maintains cytosine methylation especially in the context of CHG (where H is C, A or T) $[10,11]$. Consequently, methylated CHG sites serve as binding sites for SET and RING finger Associated (SRA)/YDG domains-containing proteins such as KRYPTONITE/SUVH4. This generates a feedback loop that expands both DNA and H3K9 methylation, which leads to chromatin compaction and gene silencing [12]. Even though multiple mechanisms (e.g., morphological, physiological, and molecular) were evolved in plants to survive their ever-changing environment, epigenetic means appear to be central in controlling gene expression and are, therefore, important for stress memory and adaptation in plants $[13,14]$. Plant response to and recovery from stresses are complex and involve the activation/repression of hundreds of genes responsible for deploying a variety of defense mechanisms to enable the plant to survive [15]. Most research related to stress tolerance has been performed under controlled growth conditions using model plants such as Arabidopsis thaliana whose genome has been sequenced and for whom a vast array of molecular tools has been developed [16]. This approach has been proven successful in isolating genes whose manipulation in plants (i.e., transgenic plants) has often conferred stress tolerance under growth-room conditions [17-20] but had only marginal effect or needs further examination under field growth conditions $[20,21]$. This is probably because, under field-growth conditions, plants are often subjected to various combinations of stresses that induce a unique response, which is different from the sum of responses to each stress when given separately [22]. Therefore, studying plants in their natural habitats (e.g., desert plants) might be a reasonable approach for unraveling novel mechanisms controlling tolerance to drought in combination with other stresses prevailing in the desert ecosystem (e.g., high temperature, high irradiation, and salinity). In this study, we investigated how the seasonal growth cycle (transition from growth to dormancy to growth) of the desert plant $Z$. dumosum in its natural habitat (characterized by extreme seasonal climate variation) is associated with epigenetic modifications and with the expression of factors regulating basic cell functions (e.g., protein synthesis, photosynthesis).

\section{Materials and Methods}

\subsection{Field Site}

The study was conducted at the Sede Boqer research area on a southeast-facing rocky slope $\left(30^{\circ} 51^{\prime} \mathrm{N} 34^{\circ} 46^{\prime} \mathrm{E}\right.$; elevation $498 \mathrm{~m}$ ), which is dominated by Zygophyllum dumosum Boiss. Specific features of the area have been described elsewhere $[23,24]$. The study spanned the years of 2007, 2009, and 2010 with an average rainfall of $164 \mathrm{~mm}$ (winter of 2006-2007), $42 \mathrm{~mm}$ (winter of 2008-2009), and $155 \mathrm{~mm}$ (winter 2009-2010), respectively. 


\subsection{Plant Materials, Acid Extraction of Proteins, and Immunoblotting}

Petioles were collected from $Z$. dumosum shrubs located on the southeast facing slope at all elevations (random sampling) every month and kept at $-80^{\circ} \mathrm{C}$ until used. Notably, old petioles were used in all experiments presented in this study. Petioles were extracted with $2 \%$ trichloroacetic acid (TCA) in NETN buffer (100 mM NaCl, $1 \mathrm{mM}$ EDTA, $20 \mathrm{mM}$ Tris, $\mathrm{pH}$ 8, and 0.5\% NP-40) and supplemented with protease inhibitor cocktail (Sigma, St. Louis, MO, USA) as described [3]. Protein concentration was determined by the Bradford reagent (BioRad, Hercules, CA, USA). Acid-soluble proteins $(10 \mu \mathrm{g})$ enriched with histones were resolved by 17\% SDS/PAGE and immunoblotted with anti-dimethylated H3K4 (Cell Signaling Technology, Danvers, MA, USA). Immuno-detection was performed using a secondary antibody of goat anti-rabbit alkaline phosphatase conjugate (Sigma) and BCIP/NBT substrate (Roche, Basel, Switzerland). Analysis of HSP proteins was performed by immunoblotting using anti-HSP70 (AS08 371, Agrisera AB, Vannas, Sweden) and anti-HSP17.6 (AS07 254, Agrisera AB, Vannas, Sweden).

\subsection{Acid Soluble Protein Extraction for Proteome Analysis}

Acid soluble proteins were extracted with $2 \%$ trichloroacetic acid and re-suspended with NETN, which was described in Reference [3]. For proteome analysis, further purification of acid soluble proteins was completed by using the methanol-chloroform method. A total of $0.8 \mathrm{~mL}$ of methanol were added to $0.2 \mathrm{~mL}$ of acid soluble proteins and mixed well by vortexing. Chloroform $(0.2 \mathrm{~mL})$ was added and the samples were vortexed and centrifuged $(10 \mathrm{~s}$ at $10,000 \times g)$. Lastly, precipitated proteins were washed by adding $0.6 \mathrm{~mL}$ methanol and the samples were mixed and centrifuged $(2 \mathrm{~min}$ at $10,000 \times g)$ to pellet the protein. The protein pellet was dried and re-suspended in phosphate buffered saline (PBS). Protein concentration was measured by using the Bradford assay (BioRad, Hercules, CA, USA).

\subsection{Proteome Analysis}

Acid soluble proteins extracted from petioles collected in the field in April and October 2007 were subjected to proteome analysis by the proteomic services of The Smoler Protein Research Center in Technion, Israel. Proteins were digested with trypsin followed by separation and mass measurement on LC-MS/MS on LTQ-Orbitrap. Mass spectrometry proteomics profiling and initial processing of the results was done by using Discoverer 1.4 against the Arabidopsis Uniprot database. All the identified peptides were filtered with high confidence, top rank, mass accuracy, and a minimum of two peptides. High confidence peptides passed the $1 \%$ FDR threshold (FDR = false discovery rate, which is the estimated fraction of false positives in a list of peptides). The area of the protein was calculated from the average of the two to three most intense peptides from each protein. Protein names and gene ontology (GO) annotations were retrieved from UniProt. GO categorization was completed by using PANTHER classification system software [25].

\subsection{DNA Extraction and Methylation Analysis}

For DNA methylation analysis, genomic DNA was extracted from petioles as described [26]. DNA was further treated with RNase A to remove RNAs followed by chloroform-isoamyl alcohol extraction and ethanol precipitation. DNA was quantified by measuring absorbance at $260 \mathrm{~nm}$ using nanodrop ND-1000 spectrophotometer and the quality of DNA was checked by using ethidium-bromide (EtBr) staining after running on $1.2 \%$ agarose gel.

DNA methylation analysis was done by using the MS-RAPD-PCR method [27]. Restriction digestion of $1 \mu \mathrm{g}$ DNA was performed separately with methylation-sensitive restriction enzymes MspI and HpaII. Then digested DNA as well as undigested controls were subjected to PCR using primers indicated at the bottom of each image. For analysis of $18 \mathrm{~S}$ rDNA, we used 18S-F-CTAGAGCTAATACGTGCAACAAACC and 18S-R-GATTGTACTCATTCCAATTACCAGAC. The PCR amplifications were performed in $10 \mu \mathrm{L}$ of a reaction mixture containing $5 \mu \mathrm{L}$ of $2 \times$ Taq PCR 
MasterMix (TIANGEN, Beijing, China), $500 \mathrm{nM}$ primers, and a $20 \mathrm{ng}$ template DNA. The amplification was performed in a Bio-rad T100 thermal cycler using the following program: $95{ }^{\circ} \mathrm{C}$ for $4 \mathrm{~min}$, 20-40 cycles of $95{ }^{\circ} \mathrm{C}, 30 \mathrm{~s}, 34^{\circ} \mathrm{C}$ or $55^{\circ} \mathrm{C}$, and $30 \mathrm{~s}, 72{ }^{\circ} \mathrm{C}, 2 \mathrm{~min}$, which was followed by a final extension of $72{ }^{\circ} \mathrm{C}, 5 \mathrm{~min}$. The PCR products were resolved on a $1.5 \%$ agarose gel and visualized by EtBr staining.

\section{Results}

\subsection{Histone H3K4 Methylation is Associated with Seasonal Growth of Z. dumosum}

We examined how rainfall levels affect $Z$. dumosum seasonal growth and gene expression activity by monitoring the level of histone H3K4 dimethyl (H3K4me2), which is a histone modification associated with transcriptionally active chromatin. Histones prepared from petioles collected each month during the years 2009 and 2010 were subjected to immunoblotting using specific H3K4me2 antibodies. The results were superimposed on the precipitation data during 2009 and 2010, which showed a clear correlation between rainfall amounts during the winter months and H3K4me2 in Z. dumosum petioles (Figure 1). Accordingly, H3K4me2 could not be detected in petioles collected in January and February of 2009, which probably resulted from insufficient and variable distribution of rainfall during the winter of 2008-2009 (42 mm, Figure 1A data from https://ims.data.gov.il/). This rendered one-year-old petioles incapable of resumption of gene expression activity and consequently growth was halted. However, two events of rainfall at the beginning and the end of March (4.3 and $18.8 \mathrm{~mm}$, respectively) allowed for growth to resume, which was accompanied by the occurrence of H3K4me2 at low levels, which persisted up to May. However, during the winter of 2010, which was rich in precipitation $(155 \mathrm{~mm})$ and displayed a well-balanced rainfall distribution (https:/ /ims.data.gov.il/), high levels of H3K4me2 were recovered from petioles collected during January and persisted up to June, which demonstrate an extended growth period. H3K4me2 is completely erased thereafter and could not be detected in petioles from July to December of 2010. This might lead to cessation of transcriptional activity, which is consistent with the reduction in nuclear size and acquisition of compact chromatin observed in Zygophyllum petioles during the dry season [3].

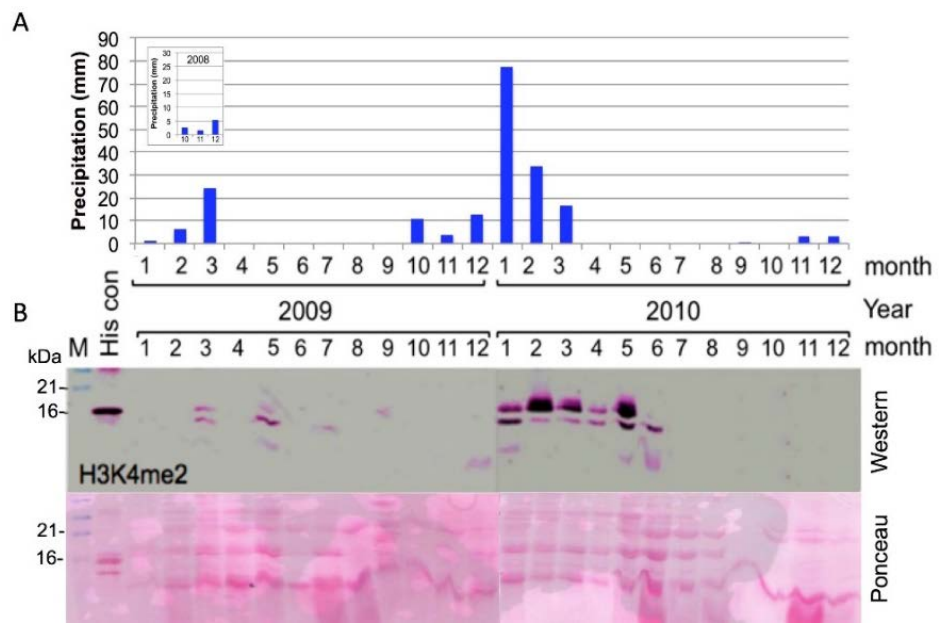

Figure 1. A positive correlation between rainfall (precipitation) and the level of H3K4me2 in Z. dumosum petioles during the years 2009 and 2010. (A) The cumulated rainfall in each month of 2009 and 2010. Inset displays the rainfall amount in October, November, and December of 2008. (B) Immunoblotting analysis of the level of histone $\mathrm{H} 3$ di-methylated at lysine 4 (H3K4me2) in Z. dumosum petioles during the years of 2009 and 2010. Acid soluble proteins ( $5 \mu \mathrm{g}$ ) were separated on 15\% SDS/PAGE and blotted onto nitrocellulose membrane, which was stained with ponceau (lower panel) and was immunoblotted with anti-H3K4me2 (upper panel). Note the high level and the extended presence of H3K4me2 in petioles collected during the rainfall-rich year of 2010. 


\subsection{DNA Methylation in Z. dumosum}

Because DNA methylation is coupled with histone methylation, we examined how the absence of di-methyl and tri-methyl H3K9 affects DNA methylation especially in the CHG context. Since genomic data of $Z$. dumosum does not exist, to address this question, we employed methylation-sensitive random sampling amplified with a polymorphic DNA-polymerase chain reaction (MS-RAPD-PCR, [27]. Genomic DNA isolated from Z. dumosum petioles collected during the wet (February 2010) and the dry (July 2010) seasons were subjected to digestion by the methylation-sensitive enzymes HpaII and MspI, which recognize the CCGG site but differ in sensitivity to methylation. Accordingly, HpaII is sensitive when either cytosine is methylated while $M s p I$ is sensitive only when the external cytosine is methylated. This distinguishes between CG and CHG methylation. Using multiple random primers as well as specific primers for the $18 \mathrm{~S}$ ribosomal DNA, we found that $\mathrm{CHG}$ methylation does occur in the genome of Z. dumosum when multiple polymorphic fragments were recovered by PCR from MspI digest (Figure 2). Accordingly, out of 15 polymorphic fragments examined, 6 fragments were exclusively methylated at the CG context, 2 at the CHG context, and 7 fragments at both CG and CHG contexts. Furthermore, 10 of these fragments showed no change in methylation in the winter and the summer, 3 underwent methylation, and 2 fragments underwent demethylation, which demonstrated that changes in methylation do occur when transitioning into the summer. Therefore, DNA methylation at the CHG context persists in Z. dumosum in spite of the lack of H3K9 di-methyl and tri-methyl. Entry into the summer is accompanied by reprogramming DNA methylation.
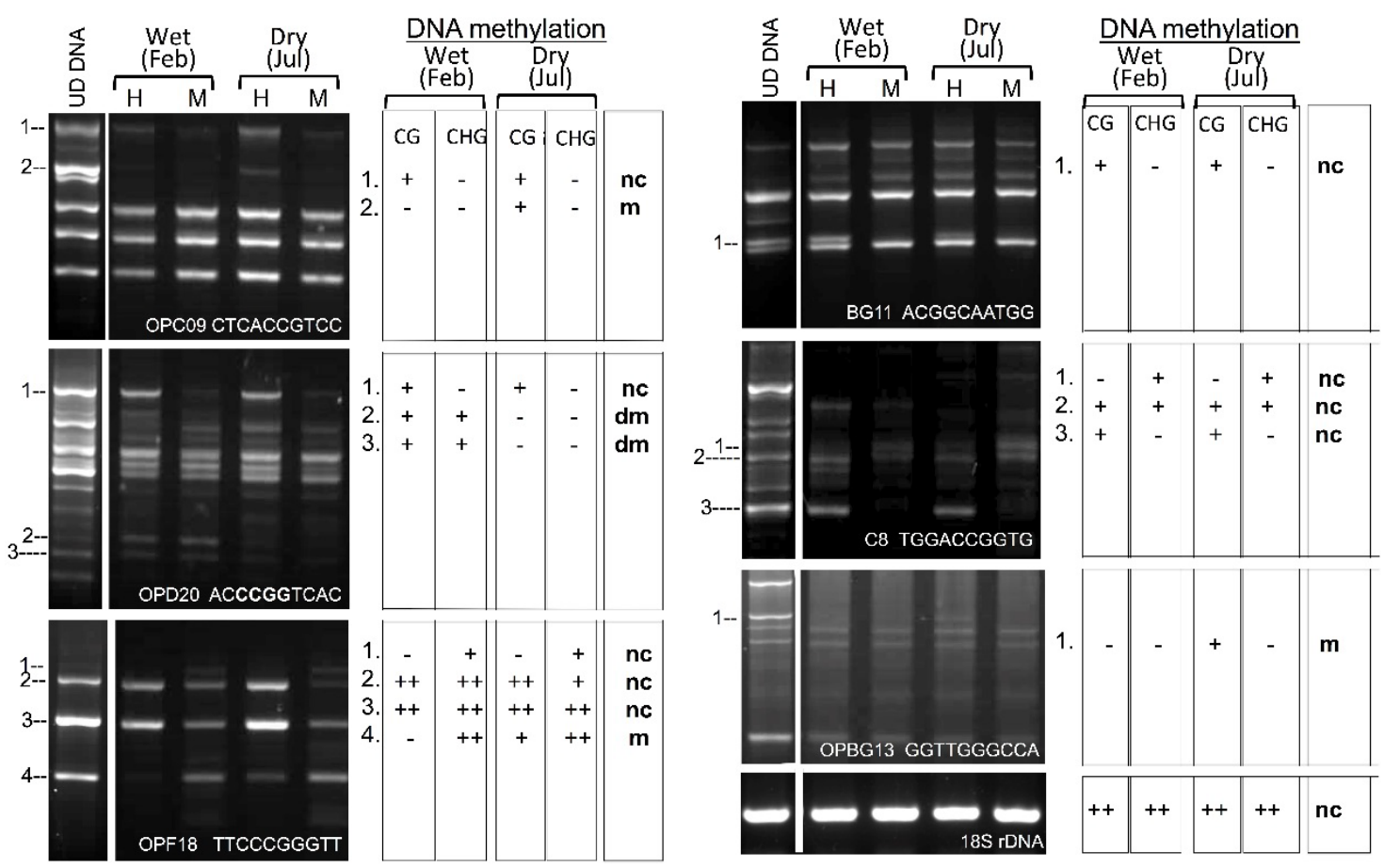

Figure 2. DNA methylation in Z. dumosum petioles collected during the wet (February) and the dry (July) seasons. A methylation-sensitive random amplified polymorphic DNA-polymerase chain reaction assay was performed using $\mathrm{HpaII}(\mathrm{H})$ and $\mathrm{Msp} \mathrm{I}(\mathrm{M})$ methylation sensitive enzymes and random primers (primer sequence is given at the bottom of each image). Polymorphic fragments are marked by numbers and the DNA methylation contexts (CG or CHG) is interpreted in the table shown on the right where ' + ' indicates positive methylation and ' - ' no methylation. Note that $18 \mathrm{~S}$ rDNA are highly methylated at both CG and CHG contexts and no change (nc) in methylation is observed between the wet and the dry season. $\mathrm{m}$ and $\mathrm{dm}$ indicate that the restriction site is undergoing methylation or demethylation, respectively, when transitioning into the dry season. 


\subsection{Seasonal Changes in Heat Shock Proteins (HSPs)}

Petioles persist during the dry, hot season and resume activity in the following wet season. We assumed that, during the dry season, HSPs commonly known as molecular chaperones might be involved in maintaining the integrity of petiole's cells by avoiding mis-folding and aggregation of proteins. We, therefore, analyzed Z. dumosum response to seasonal temperature variation by measuring the level of HSPs in petioles in each month of the year of 2009. We used immunoblotting with antibodies to HSP70 and to small HSP17.6 proteins. Small HSPs are known to be induced following exposure of plants to various stress conditions and are assumed to play a role in stress tolerance [28]. The results show (Figure 3B) a distinct expression pattern of HSP70 and HSP17.6 in Z. dumosum petioles during the year. While HSP70 is expressed in petioles collected during winter and spring months, its expression was reduced significantly during the summer months (July to October). However, HSP17.6 was restrictively expressed during the months displaying the highest temperatures, which are the months of June to August. No expression or low expression is evident in other months of the year.

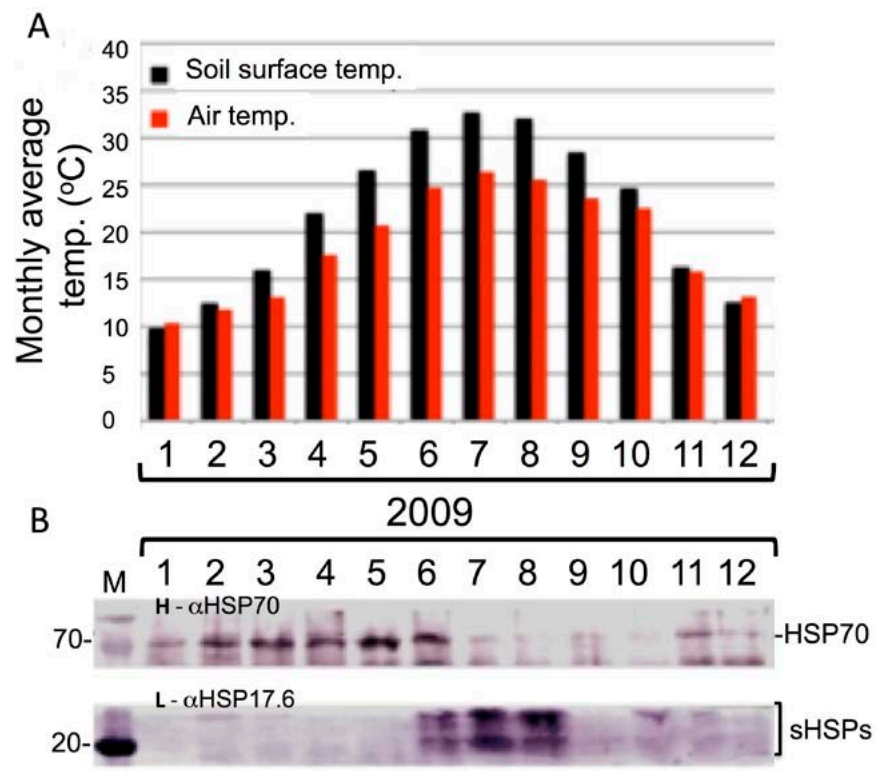

Figure 3. Expression of heat shock proteins in Z. dumosum petioles during the year of 2009. (A) The monthly average temperature $\left({ }^{\circ} \mathrm{C}\right.$ ) of the air (red column) and the soil surface (black column) in each month of 2009. (B) Total proteins extracted from petioles collected in each month of 2009 were separated on $12 \%$ SDS/PAGE, and blotted. The membrane was stained with ponceau and cut into two parts containing high $(\mathrm{H})$ and low $(\mathrm{L})$ molecular weight proteins. The high and low membranes were subjected to immunoblotting using anti-HSP70 ( $\alpha$ HSP70) and anti-HSP17.6. ( $\alpha$ HSP17.6), respectively. Note that antibodies to HSP17.6 can potentially recognize other small HSPs (sHSPs) since they share significant amino acid sequence homology. The molecular mass (M) is given on the left in $\mathrm{kDa}$.

\subsection{Changes in Acid Soluble Proteins in Petioles During the Transition from the Wet to the Dry Season}

The dormant state assumed by Z. dumosum during the summer is retained even when Zygophyllum shrubs were irrigated when they failed to evoke cambial activity or leaf development [4]. Obviously, at the onset of entry into a dormant state, at the beginning of the summer, Z. dumosum undergoes extensive changes in the gene expression pattern associated with chromatin compaction [3] and disappearance of $\mathrm{H} 3 \mathrm{~K} 4 \mathrm{me} 2$, which leads to a significant reduction in cellular activities. To address how the reduction in cell activity is achieved, we performed proteome analysis to identify basic proteins including histones and ribosomal proteins operating during the wet and the dry seasons. To this end, petioles were collected from Z. dumosum in 2007 during the wet season (April 2007) and the end of the dry season (October 2007) (see Figure 4A). These petioles were subjected to acid extraction 
(to enrich for basic proteins) followed by proteome analysis by LC-MS/MS and identification by Discoverer software against the Arabidopsis Uniprot database. Notably, the analysis of the permissive epigenetic marker dimethyl H3K4 during the winter of 2007 was previously described [3], which revealed persistence of dimethyl H3K4 up to July. This further supported the correlation between rainfall amount and distribution as well as growth and the persistence of H3K4me2 in Z. dumosum petioles. The proteome data (Figure 4B and Supplementary Table S1) revealed 189 proteins in which 187 were recovered from winter petioles and 151 from summer petioles. Among the 187 proteins recovered in winter petioles, 82 proteins were either significantly reduced ( 44 proteins) or were absent (38 proteins) in summer petioles (Figure 4B, Supplementary Table S1). Functional categorization (PANTHER classification system) of these 82 proteins revealed (Figure $4 \mathrm{C}$ ) that among the 55 proteins recognized in the protein class category, 24 proteins are involved in nucleic acid binding (most of which are ribosomal proteins; Table 1), five proteins are chloroplastic hydrolases (Table 1), and eight proteins are essentially mitochondrial oxireductases/dehydrogenases (Table 1). Among the 151 proteins recovered in summer petioles, 17 proteins were either upregulated (15 proteins) or were absent in winter petioles and are induced in the summer (two proteins) (Table 2). Among these 17 upregulated proteins, three proteins are related to the ubiquitin system including the polyubiquitin precursor protein (related to Arabidopsis UBQ10, At4g05320) and ubiquitin conjugates known as the Ubiquitin-60S ribosomal protein L40-2 and the Ubiquitin-40S ribosomal protein S27a-2. Notably, the levels of core histone proteins remain essentially unchanged in the wet and the dry season except for a notable reduction in histone $\mathrm{H} 4$ during the dry season (Supplementary Table S1).

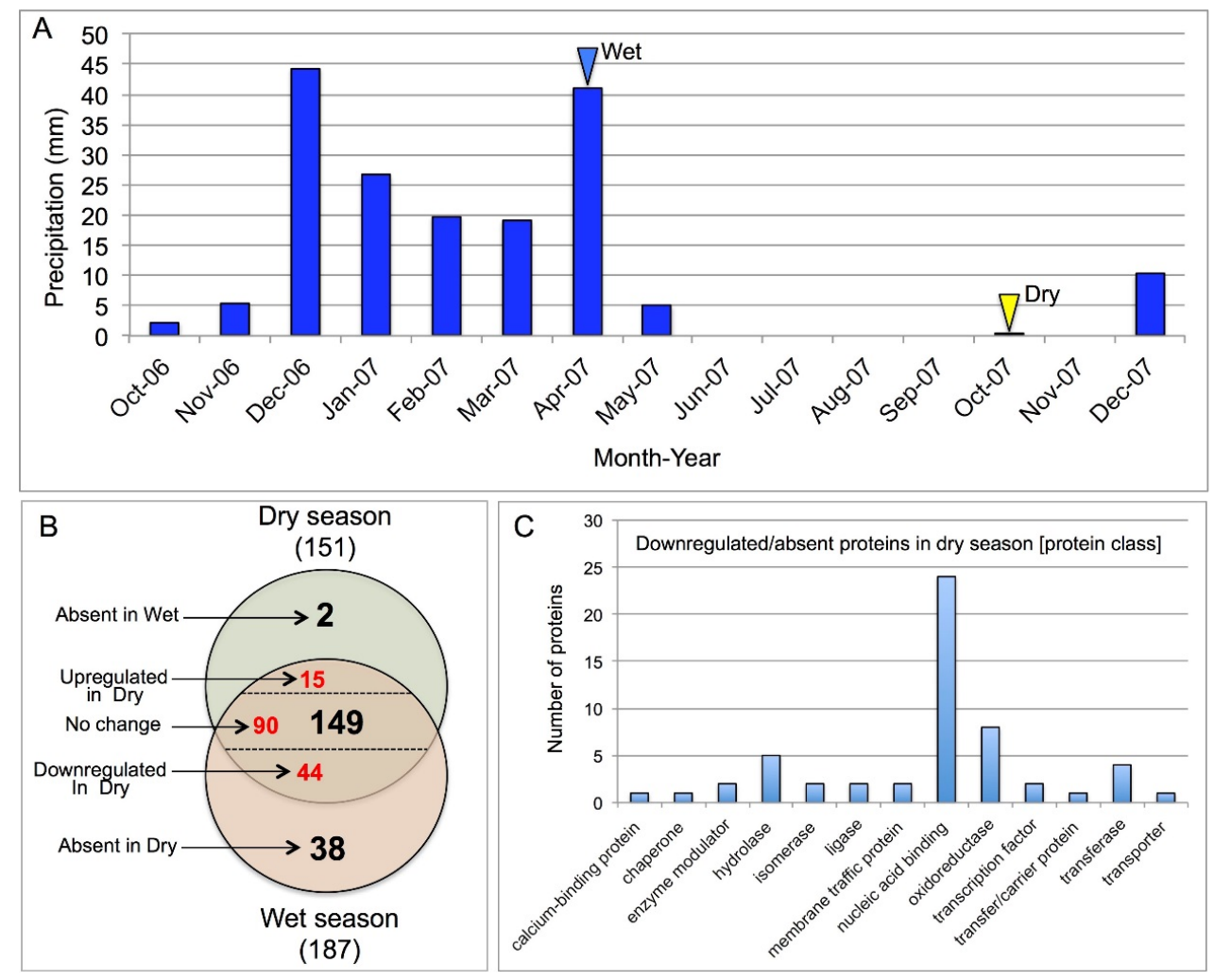

Figure 4. Proteome analysis of acid soluble proteins extracted from Z. dumosum petioles in the wet and the dry seasons. (A) The cumulated rainfall in the indicated months of 2006 and 2007. Blue and yellow arrowheads indicate the wet and the dry months, respectively, in which petioles were collected for proteome analysis. (B) The venn diagram shows the number of proteins recovered from petioles during the wet and the dry seasons. (C) Categorization analysis (Protein class) using the PANTHER classification system of 82 proteins that were down-regulated or absent in the dry season petioles. Notably, most proteins related to the nucleic acid binding class are ribosomal proteins (see Table 1). 
Table 1. List of nucleic acid binding proteins, oxireductases/dehydrogenases and hydrolases, which are significantly down-regulated in Z. dumosum petioles in the dry season. (M, mitochondria; Ch, chloroplast).

\begin{tabular}{|c|c|c|c|}
\hline \multicolumn{4}{|c|}{ Nucleic Acid Binding Proteins } \\
\hline Accession & $\begin{array}{l}\text { Arabidopsis } \\
\text { Gene ID }\end{array}$ & Gene Name/Gene Symbol Ortolog & Ratio Wet/Dry \\
\hline Q93VC7 & At5g30510 & 30S ribosomal protein S1; RPS1 (Ch) & 30.40 \\
\hline F4J3P1 & At1g04480 & 60 S ribosomal protein L23; RPL23A & 5.71 \\
\hline Q8VZB9 & At1g08360 & $60 S$ ribosomal protein L10a-1; RPL10AA & 12.02 \\
\hline O04527 & At1g70190 & F20P5.9 protein & Not found in dry season \\
\hline Q9SJ36 & At2g05220 & $40 \mathrm{~S}$ ribosomal protein S17-2; RPS17B & Not found in dry season \\
\hline P46286 & At2g18020 & $60 S$ ribosomal protein L8-1; RPL8A & Not found in dry season \\
\hline Q39244 & At2g 47580 & $\mathrm{U} 1$ small nuclear ribonucleoprotein $\mathrm{A}$; U1A & 64.76 \\
\hline A0A1P8AW31 & At3g02540 & Ubiquitin receptor RAD23c; RAD23C & Not found in dry season \\
\hline Q9LK61 & At3g13120 & 30S ribosomal protein S10; RPS10 (Ch) & Not found in dry season \\
\hline O23290 & At3g23390 & 60S ribosomal protein L36a; RPL36AA & Not found in dry season \\
\hline P42036 & At3g52580 & $40 \mathrm{~S}$ ribosomal protein S14-3; RPS14C & 5.63 \\
\hline P38666 & At3g53020 & $60 S$ ribosomal protein L24-2; RPL24B & 7.56 \\
\hline Q9M352 & At3g53740 & $60 S$ ribosomal protein L36-2; RPL36B & 59.70 \\
\hline A8MS83 & At3g55280 & $60 S$ ribosomal protein L23a-2; RPL23AB & 21.34 \\
\hline Q9LZH9 & At3g62870 & $60 S$ ribosomal protein L7a-2; RPL7AB & Not found in dry season \\
\hline Q9M1X0 & At3g63190 & Ribosome-recycling factor; RRF (Ch) & 23.60 \\
\hline P49693 & At4g02230 & 60 ribosomal protein L19-3; RPL19C & 34.07 \\
\hline Q9SZD6 & At4g29060 & Elongation factor Ts, emb2726 (M) & Not found in dry season \\
\hline Q9M0E2 & At4g29410 & $60 \mathrm{~S}$ ribosomal protein L28-2; RPL28C & 4.44 \\
\hline Q93VG5 & At5g20290 & 40S ribosomal protein S8-1; RPS8A & 14.12 \\
\hline Q9FI15 & At5g 44500 & Small nuclear ribonucleoprotein-associated protein & Not found in dry season \\
\hline P55228 & At5g48300 & Glucose-1-phosphate adenylyltransferase small subunit & Not found in dry season \\
\hline A8MQA1 & At3g49010 & 60S ribosomal protein L13-1; RPL13B & 6.94 \\
\hline Q9FNP8 & At5g61170 & $40 \mathrm{~S}$ ribosomal protein S19-3; RPS19C & Not found in dry season \\
\hline \multicolumn{4}{|c|}{ Oxireductases/dehydrogenases } \\
\hline Q9M5K3 & At1g48030 & Dihydrolipoyl dehydrogenase $1,(\mathbf{M})$ & 8.71 \\
\hline F4HNZ6 & At1g12900 & Glyceraldehyde-3-phosphate dehydrogenase, (Ch) & 4.6 \\
\hline Q9ZP06 & At1g53240 & Malate dehydrogenase $1,(\mathbf{M})$ & 4.45 \\
\hline A0A1P8BD41 & At5g52840 & $\begin{array}{l}\text { NADH dehydrogenase } 1 \text { alpha subcomplex subunit } 5,(\mathbf{M}) \\
\text { Complex I, non-core accessory subunit B13 }\end{array}$ & Not found in dry season \\
\hline F4JWS9 & At5g25450 & Cytochrome b-c1 complex subunit 7-2;QCR7-2 Complex III & 3.99 \\
\hline Q9ZNZ7 & At5g04140 & Ferredoxin-dependent glutamate synthase 1, (Ch/M) & Not found in dry season \\
\hline Q94B78 & At4g33010 & Glycine dehydrogenase (decarboxylating) 1, GLDP1 (M) & Not found in dry season \\
\hline A0Ā1P8B993 & At3g14420 & Peroxisomal (S)-2-hydroxy-acid oxidase GLO1 & Not found in dry season \\
\hline \multicolumn{4}{|c|}{ Hydrolases } \\
\hline Q9SSS9 & At4g09650 & ATP synthase subunit delta (Ch) AtpD; HCP & not found in dry season \\
\hline PODKC4 & At5g36790 & Phosphoglycolate phosphatase 1B, PGLP1B (Ch) & not found in dry season \\
\hline P25851 & At3g54050 & Fructose-1,6-bisphosphatase 1, CFBP1 (Ch) & not found in dry season \\
\hline Q9ZNZ7 & At5g04140 & Ferredoxin-dependent glutamate synthase $1,(\mathbf{C h} / \mathbf{M})$ & not found in dry season \\
\hline O80860 & At2g30950 & ATP-dependent zinc metalloprotease FTSH 2 (Ch) & 5.7 \\
\hline
\end{tabular}

We also identified a small heat shock protein called HSP17.4 whose level is significantly increased (more than six-fold) in petioles during the dry season when compared to the wet season. In addition, upregulation in Z. dumosum petioles during the dry season include two HSP90 proteins, which are related to the Arabidopsis HSP90 cluster III having 2-3 introns [29] as well as HSP70B (related to Arabidopsis At1g16030), which is implicated in response to heat stress [30]. 
Table 2. List of proteins significantly up-regulated in Z. dumosum petioles in the dry season. Ch, chloroplasts.

\begin{tabular}{cccc}
\hline Accession & $\begin{array}{c}\text { Related to } \\
\text { Arabidopsis } \\
\text { Gene ID }\end{array}$ & Gene Name/Gene Symbol Ortolog & Ratio Wet/Dry \\
\hline Q9ZUC1 & At1g23740 & NADPH-dependent alkenal/one oxidoreductase (Ch) & 0.1 \\
O80977 & At2g14740 & Vacuolar-sorting receptor 3 & 0.1 \\
OAP01990.1 & At3g40120 & HSP17.4 & 0.2 \\
Q9SRZ6 & At165930 & Cytosolic isocitrate dehydrogenase [NADP] & 0.2 \\
P27323 & At5g52640 & Heat shock protein 90-1 & 0.2 \\
Q9SYT0 & At1g35720 & Annexin D1 & 0.3 \\
Q94JQ4 & At3g20390 & Reactive Intermediate Deaminase A (Ch) & 0.3 \\
O49006 & At3g14310 & Pectinesterase/pectinesterase inhibitor 3 & 0.3 \\
A0A1I9LT03 & At3g03250 & UDP-GLUCOSE PYROPHOSPHORYLASE 1 & 0.3 \\
ABH08753.1 & At4g5320 & ubiquitin & 0.4 \\
Q42202 & At2g36170 & Ubiquitin-60S ribosomal protein L40-2 & 0.4 \\
F4IGK5 & At2g21250 & NAD(P)-linked oxidoreductase superfamily protein & 0.4 \\
O03986 & At5g56000 & Heat shock protein 90-4 & 0.5 \\
P59232 & At2g47110 & Ubiquitin-40S ribosomal protein S27a-2 & 0.5 \\
F4JZ46 & At5g66190 & Ferredoxin-NADP reductase & 0.5 \\
Q9S9N1 & At1g16030 & Heat shock 70 kDa protein 5 & Not found in wet season \\
Q9ZSJ7 & At3g24160 & Peroxisome membrane protein (PMP) & Not found in wet season \\
\hline
\end{tabular}

\section{Discussion}

Plant species flourishing in desert environments have evolved multiple mechanisms that enable them to respond to extremely variable seasonal climate conditions occurring during the wet and the dry seasons. Obviously, the dry summer poses challenges to desert plants including long periods of high temperatures, high radiation, and water scarcity. Yet, the summer is stable and predictable and many plants thriving in arid and semi-arid regions shut down growth and enter into a dormant state, which is an adaptive trait conferring survival under severe drought conditions [31,32]. Most studies related to summer dormancy focused on perennial grasses inhabiting arid and semi-arid regions, which showed that dormancy is commonly induced by several environmental factors including long days, high temperatures, and a water deficit [33-35]. In Z. dumosum, a water deficit appears to be the major factor inducing summer dormancy, and growth can persist under long days and high temperatures as far as water is available. Notably, once it enters into a dormant state, further irrigation will not cause growth or any significant physiological activities, under long days and high temperatures [4]. Similarly, our attempts to resume growth by irrigating Z. dumosum shrubs in the middle of August (2009) failed. In contrast, Terwilligner and Zeroni (1994) reported that irrigation of Z. dumosum in the middle of July resulted in the emergence of new leaflets (that is, new compound leaves emerging from the axil of the remaining phyllode/petiole) within two weeks. These controversial results may be attributed to the site of study. Accordingly, the Terwilligner and Zeroni (1994) study was conducted on a northeastern-facing slope, which is expected to dry out slowly relative to the southeastern-facing slope (the site of the present study). We, therefore, assume that the appearance of new leaves following irrigation in the middle of July is because the shrub is not yet fully dormant and can respond to ephemeral inputs of water by resuming growth.

The winter that represents the growing season poses difficulties to desert plants because the temperature largely fluctuates. Rainfall is low and is often highly variable both in space and time. Consequently, desert plants have inherent capabilities to withstand extreme seasonal climate changes and fluctuations in resource availability via a multitude of strategies (morphological and molecular) that operate together to bring about plant survival in the desert ecosystem. We described in this paper some molecular mechanisms operating in the desert plant Z. dumosum under seasonal climate change. Seasonal growth activity during the wet season is highly correlated with the rainfall and associated with the transcriptional epigenetic marker of histone $\mathrm{H3}$ methylated at lysine 4 [36,37]. Accordingly, in years with a high amount of rainfall and a balanced rainfall distribution, the permissive epigenetic 
mark (H3K4me2) persists for a long period ranging from January to June or July [3]. However, in years with poor and unbalanced distribution of rainfall, H3K4me2 is relatively low and restricted to months experiencing a generous amount of rainfall. The disappearance of $\mathrm{H} 3 \mathrm{~K} 4 \mathrm{me} 2$ from petioles during the summer suggests complete withdrawal from growth and entry into summer dormancy as soon as the dry season starts. Therefore, the epigenetic marker H3K4me2 appears to be a reliable indicator for plant growth activity in a variable desert environment.

In Arabidopsis, DNA methylation in the context of CHG appears to be coupled to histone H3K9 methylation in a feedback loop, which involves two epigenetic factors known as CMT3 and SUVH4/KYP. Accordingly, SUVH4/KYP methylates histone H3K9 generates a binding site for CMT3 that methylates cytosine in the context of CHG $[10,11]$. Consequently, methylated CHG sites serve as binding sites for SET and Ring finger Associated (SRA)/YDG domains-containing proteins such as SUVH4/KYP, which generates a feedback loop that expands both DNA and H3K9 methylation. This leads to chromatin compaction and gene silencing [12]. Loss of CHG methylation found in the suvh4/kyp mutant mimicked the loss of CHG methylation observed in the cmt3 mutant [38]. Therefore, histone H3K9 methylation is required for CHG methylation mediated by CMT3. The findings that Z. dumosum does not possess di-methyl and tri-methyl H3K9 [3] prompted us to investigate the consequences for DNA methylation. The data presented in this paper clearly showed that DNA methylation is not affected in Z. dumosum in spite of a lack of di-methyl and tri-methyl H3K9. This can be explained by the persistence in Z. dumosum of monomethyl H3K9, which might be sufficient for directing CMT3 non-CG methylation genome-wide. Indeed, CMT3 can bind efficiently to H3K9 when it is mono-methylated, di-methylated, or tri-methylated [9]. Lastly, we observed changes in DNA methylation during the transition from the wet to the dry season and the acquisition of dormant state linking Z. dumosum seasonal growth with epigenetic reprogramming of gene expression. Similarly, changes in the DNA methylation pattern were observed during winter dormancy in an apple [39]. The effect of stress on epigenetic modification of histones and DNA has been well documented and is assumed to contribute to plant stress tolerance [40-42].

Proteome data of acid-soluble proteins extracted from petioles during the wet and the dry seasons revealed some molecular means for acquiring a dormant state as well as maintaining cellular integrity. Accordingly, the transition into the dry season resulted in the disappearance or significant reduction in ribosomal proteins. This massive reduction in ribosomal proteins might halt protein synthesis and facilitate the cessation of growth and entry into a dormant state. The proteome data also pointed to a reduction in photosynthesis and respiration activities as evidenced by reduction in hydrolytic enzymes residing in the chloroplasts such as Fructose-1,6-bisphosphatase 1, Ferredoxin-dependent glutamate synthase, and ATP synthase subunit delta as well as in the mitochondria such as Dihydrolipoyl dehydrogenase and NADH-ubiquinone oxidoreductase (Table 1). It appears that, during the dry season, certain vital activities are either lost or significantly reduced in the remaining petioles including protein synthesis, photosynthesis, and respiration, which allow dormancy and survival under extreme environments. This dormant state is further reinforced by increasing the levels of the polyubiquitin precursor protein and ubiquitin conjugated to ribosomal proteins known as orthologs of ubiquitin-RPL40 and ubiquitin-RPS27. The covalent conjugation of ubiquitin to substrate proteins (via ubiquitin lysine 48) directs them to undergo proteolysis in the proteasome system [43], which might be instrumental in controlling the dormant state attained by cells during the dry season. The function of ubiquitin conjugated to ribosomal proteins is not fully understood. Recent work in animals highlighted the central roles of ubiquitin-coding gene UBA52, encoding for a mono-ubiquitin fuses at its C-terminus to the ribosomal protein L40 (RPL40), and in the regulation of the physiological level of ubiquitin and ribosomal functionality [44]. The accumulation of ubiquitin-RPL40 and ubiquitin-RPS27 in Z. dumosum petioles during the summer may be attributed to a lack of de-ubiquitinases, which are enzymes that recycle ubiquitin from ubiquitin conjugates or ubiquitin precursors [45].

We observed seasonal variation in HSP proteins associated with temperature variation, particularly, small HSP proteins found in high amounts during the dry season and in low amounts 
during the wet season (Figure 3). This is consistent with the proteome data showing an increase in the levels of HSP proteins, which include small HSP17.4, HSP90, and HSP70B found during the dry season. Expression of small HSP proteins (sHSPs) is induced following exposure to various stress conditions including heat, drought, and salt and has been correlated with stress tolerance [28]. HSP70B appears to be expressed exclusively during heat stress [30] and might be involved in thermo-tolerance. It assists in refolding of denatured proteins [46]. In the absence of stress, sHSPs expression is restricted to certain developmental stages including embryo and pollen development and germination [28]. The mechanism by which sHSPs confer stress tolerance is not well understood. Some sHSPs as well as HSP90 were shown to act as molecular chaperones stabilizing and assisting proper protein folding [47-49]. This function may explain why these non-basic HSP proteins are extractable in acidic buffer. Accordingly, we suggest that HSP proteins are physically associated with basic proteins during the dry season (and, therefore, are co-extracted with them) to maintain the integrity of cells by protecting proteins from unfolding and aggregation and keeping them in a competent state for correct folding once growth is resumed.

\section{Conclusions}

Multiple mechanisms evolved in the desert plant Z. dumosum to allow for its survival under extreme seasonal climate changes. Like other plants, its growth cycles and productivity are highly dependent on the availability of water $[50,51]$ and are associated with the presence of the permissive epigenetic marker of di-methyl H3K4. Clearly, acquisition of a dormant state during the dry season is an important mechanism for adaptation and survival to multiple abiotic stresses, which are expected to increase in frequency and severity due to global warming [5]. Summer dormancy in Z. dumosum is achieved by depriving the permissive epigenetic marker di-methyl H3K4, which, in turn, facilitates the acquisition of compact chromatin conformation [3] as well as by a significant reduction in proteins involved in basic cell functions such as protein synthesis, photosynthesis, and respiration. Some proteins may be associated with HSP-chaperones whose levels are increased during the dry season to ensure the integrity of cellular components. Certain epigenetic markers such as di-methyl and tri-methyl H3K9 have been lost in Z. dumosum [3] and in all examined Zygophyllaceae species that inhabit dry and semidry regions of the world [7]. This suggests that lessening epigenetic constraints might have an adaptive value in variable, unpredictable environments, which provides plants with opportunistic capabilities such as a prompt response to their ever-changing environment to allow for rapid exploitation of transient input of resources. Although multiple mechanisms were evolved to bring about plant tolerance in variable desert environments, epigenetic means appear to be central in controlling gene expression and are, therefore, important for stress memory and adaptation in plants $[14,52]$. We, therefore, anticipate that plants in general—and desert plants in particular-may be resilient to climate change [53] based on the existence of a plethora of mechanisms for stress tolerance and the potential to attenuate the effect of extreme environmental conditions through prompt manipulation of the epigenetic landscapes.

Supplementary Materials: The following are available online at http:/ /www.mdpi.com/2223-7747/7/3/59/s1. Table S1: A Combined list of proteins recovered from Zygophyllum petioles collected in the field during the wet (April) and the dry (October) seasons.

Author Contributions: Conceptualization, G.G. (Gideon Grafi); Methodology, G.G. (Gila Granot); Validation, G.G. (Gila Granot), J.K. and N.S.Y.; Investigation, G.G. (Gila Granot), J.K. and N.S.Y.; Resources, G.G. (Gideon Grafi) and G.G. (Gila Granot); Data Curation, G.G. (Gideon Grafi) and J.K.; Writing-Original Draft Preparation, G.G. (Gideon Grafi); Writing-Review \& Editing, G.G. (Gideon Grafi), G.G. (Gila Granot), J.K. and N.S.Y.; Visualization, G.G. (Gideon Grafi); Supervision, G.G. (Gideon Grafi); Project Administration, G.G. (Gideon Grafi); Funding Acquisition, G.G. (Gideon Grafi) and N.S.Y.

Funding: This research was funded by the Goldinger Trust of the Jewish Fund for the Future at the Jewish Federation of Delaware to G.G, and by the PBC Program of Israeli Council for Higher Education and of the Blaustein Center for Scientific Cooperation post-doctoral fellowships to NSY.

Acknowledgments: We thank members of the lab for helping in collecting plant materials. 
Conflicts of Interest: The authors declare no conflicts of interest.

\section{References}

1. Bray, E.A.; Bailey-Serres, J.; Weretilnyk, E. Responses to abiotic stresses. In Biochemistry and Molecular Biology of Plants; Gruissem, W., Buchannan, B., Jones, R., Eds.; American Society of Plant Physiologists: Rockville, MD, USA, 2000; pp. 1158-1249.

2. Danin, A. Desert Vegetation of Israel and Sinai; Cana Publishing House: Jerusalem, Israel, 1983; pp. 1-148.

3. Granot, G.; Sikron-Persi, N.; Gaspan, O.; Florentin, A.; Talwara, S.; Paul, L.K.; Morgenstern, Y.; Granot, Y.; Grafi, G. Histone modifications associated with drought tolerance in the desert plant Zygophyllum dumosum Boiss. Planta 2009, 231, 27-34. [CrossRef] [PubMed]

4. Waisel, Y.; Liphschitz, N.; Fahn, A. Cambial activity in Zygophyllum dumosum Boiss. Ann. Bot. 1970, 34, 409-414. [CrossRef]

5. Gillespie, L.M.; Volaire, F.A. Are winter and summer dormancy symmetrical seasonal adaptive strategies? The case of temperate herbaceous perennials. Ann. Bot. 2017, 119, 311-323. [CrossRef] [PubMed]

6. Volaire, F.A. A unified framework of plant adaptive strategies to drought: Crossing scales and disciplines. Glob. Chang. Biol. 2018, 24, 2929-2938. [CrossRef] [PubMed]

7. Granot, G.; Grafi, G. Epigenetic information can reveal phylogenetic relationships within Zygophyllales. Plant Syst. Evol. 2014, 300, 1819-1824. [CrossRef]

8. Thorstensen, T.; Grini, P.E.; Aalen, R.B. SET domain proteins in plant development. Biochim. Biophys. Acta 2011, 1809, 407-420. [CrossRef] [PubMed]

9. Stroud, H.; Do, T.; Du, J.; Zhong, X.; Feng, S.; Johnson, L.; Patel, D.J.; Jacobsen, S.E. Non-CG methylation patterns shape the epigenetic landscape in Arabidopsis. Nat. Struct. Mol. Biol. 2014, 21, 64-72. [CrossRef] [PubMed]

10. Lindroth, A.M.; Cao, X.; Jackson, J.P.; Zilberman, D.; McCallum, C.M.; Henikoff, S.; Jacobsen, S.E. Requirement of CHROMOMETHYLASE3 for maintenance of CpXpG methylation. Science 2001, 292, 2077-20780. [CrossRef] [PubMed]

11. Bartee, L.; Malagnac, F.; Bender, J. Arabidopsis cmt3 chromomethylase mutations block non-CG methylation and silencing of an endogenous gene. Genes Dev. 2001, 15, 1753-1758. [CrossRef] [PubMed]

12. Johnson, L.M.; Bostick, M.; Zhang, X.; Kraft, E.; Henderson, I.; Callis, J.; Jacobsen, S.E. The SRA methyl-cytosine-binding domain links DNA and histone methylation. Curr. Biol. 2007, 17, 379-384. [CrossRef] [PubMed]

13. Bräutigam, K.; Vining, K.J.; Lafon-Placette, C.; Fossdal, C.G.; Mirouze, M.; Marcos, J.G.; Fluch, S.; Fraga, M.F.; Guevara, M.Á.; Abarca, D.; et al. Epigenetic regulation of adaptive responses of forest tree species to the environment. Ecol. Evol. 2013, 3, 399-415. [CrossRef] [PubMed]

14. Lämke, J.; Bäurle, I. Epigenetic and chromatin-based mechanisms in environmental stress adaptation and stress memory in plants. Gen. Biol. 2017, 18, 124. [CrossRef] [PubMed]

15. Chen, W.J.; Zhu, T. Networks of transcription factors with roles in environmental stress response. Trends Plant Sci. 2004, 9, 591-596. [CrossRef] [PubMed]

16. Bressan, R.A.; Zhang, C.; Zhang, H.; Hasegawa, P.M.; Bohnert, H.J.; Zhu, J.K. Learning from the Arabidopsis experience. The next gene search paradigm. Plant Physiol. 2001, 127, 1354-1360. [CrossRef] [PubMed]

17. Karaba, A.; Dixit, S.; Greco, R.; Aharoni, A.; Trijatmiko, K.R.; Marsch-Martinez, N.; Krishnan, A.; Nataraja, K.N.; Udayakumar, M.; Pereira, A. Improvement of water use efficiency in rice by expression of HARDY, an Arabidopsis drought and salt tolerance gene. Proc. Natl. Acad. Sci. USA 2007, 104, 15270-15275. [CrossRef] [PubMed]

18. Zhang, G.; Chen, M.; Li, L.; Xu, Z.; Chen, X.; Guo, J.; Ma, Y. Overexpression of the soybean GmERF3 gene, an AP2/ERF type transcription factor for increased tolerances to salt, drought, and diseases in transgenic tobacco. J. Exp. Bot. 2009, 60, 3781-3796. [CrossRef] [PubMed]

19. Wu, X.; Shiroto, Y.; Kishitani, S.; Ito, Y.; Toriyama, K. Enhanced heat and drought tolerance in transgenic rice seedlings overexpressing OsWRKY11 under the control of HSP101 promoter. Plant Cell Rep. 2009, 28, 21-30. [CrossRef] [PubMed]

20. Wang, H.; Wang, H.; Shao, H.; Tang, X. Recent Advances in Utilizing Transcription Factors to Improve Plant Abiotic Stress Tolerance by Transgenic Technology. Front. Plant Sci. 2016, 7, 67. [CrossRef] [PubMed] 
21. Serraj, R.; Sinclair, T.R. Osmolyte accumulation: Can it really help increase crop yield under drought conditions? Plant Cell Environ. 2002, 25, 333-341. [CrossRef] [PubMed]

22. Mittler, R. Abiotic stress, the field environment and stress combination. Trends Plant Sci. 2006, 11, 15-19. [CrossRef] [PubMed]

23. Herwitz, S.R.; Olsvig-Whittaker, L. Preferential Upslope Growth of Zygophyllum dumosum Boiss. (Zygophyllaceae) Roots into Bedrock Fissures in the Northern Negev Desert. J. Biogeogr. 1989, 16, 457-460. [CrossRef]

24. Terwilliger, V.J.; Zeroni, M. Gas exchange of a desert shrub (Zygophyllum dumosum Boiss.) under different soil moisture regimes during summer drought. Vegetatio 1994, 115, 133-144.

25. Mi, H.; Muruganujan, A.; Casagrande, J.T.; Thomas, P.D. Large-scale gene function analysis with the PANTHER classification system. Nat. Protoc. 2013, 8, 1551-1566. [CrossRef] [PubMed]

26. Dellaporta, S.L.; Wood, J.; Hicks, J.B. A plant DNA minipreparation: Version II. Plant Mol. Biol. Rep. 1983, 1, 19-21. [CrossRef]

27. Singh, K.P. Screening of DNA methylation changes by methylation-sensitive random amplified polymorphic DNA-polymerase chain reaction (MS-RAPD-PCR). Methods Mol. Biol. 2014, 1105, 71-81. [PubMed]

28. Sun, W.; Van Montagu, M.; Verbruggen, N. Small heat shock proteins and stress tolerance in plants. Biochim. Biophys. Acta 2002, 1577, 1-9. [CrossRef]

29. Xu, Z.S.; Li, Z.Y.; Chen, Y.; Chen, M.; Li, L.C.; Ma, Y.Z. Heat shock protein 90 in plants: Molecular mechanisms and roles in stress responses. Int. J. Mol. Sci. 2012, 13, 15706-15723. [CrossRef] [PubMed]

30. Sung, D.Y.; Vierling, E.; Guy, C.L. Comprehensive expression profile analysis of the Arabidopsis Hsp70 gene family. Plant Physiol. 2001, 126, 789-800. [CrossRef] [PubMed]

31. Volaire, F.; Norton, M. Summer dormancy in perennial temperate grasses. Ann. Bot. 2006, 98, 927-933. [CrossRef] [PubMed]

32. Shaimi, N.; Kallida, R.; Volaire, F.; Saidi, N.; Al Faiz, C. Summer dormancy and drought survival of Moroccan ecotypes of orchardgrass. Crop Sci. 2009, 49, 1416-1424. [CrossRef]

33. Laude, H.M. The nature of summer dormancy in perennial grasses. Bot. Gaz. 1953, 114, 284-292. [CrossRef]

34. Ofir, M.; Kerem, D. The effects of temperature and photoperiod on the onset of summer-dormancy in Poa bulbosa L. Ann. Bot. 1982, 50, 259-264. [CrossRef]

35. Ofir, M.; Kigel, J. Regulation of summer dormancy by water deficit and ABA in Poa bulbosa ecotypes. Ann. Bot. 2007, 99, 293-299. [CrossRef] [PubMed]

36. Li, X.; Wang, X.; He, K.; Ma, Y.; Su, N.; He, H.; Stolc, V.; Tongprasit, W.; Jin, W.; Jiang, J.; et al. High-resolution mapping of epigenetic modifications of the rice genome uncovers interplay between DNA methylation, histone methylation, and gene expression. Plant Cell 2008, 20, 259-276. [CrossRef] [PubMed]

37. Zhang, X.; Bernatavichute, Y.V.; Cokus, S.; Pellegrini, M.; Jacobsen, S.E. Genome-wide analysis of mono-, di- and trimethylation of histone H3 lysine 4 in Arabidopsis thaliana. Gen. Biol. 2009, 10, R62. [CrossRef] [PubMed]

38. Stroud, H.; Greenberg, M.V.; Feng, S.; Bernatavichute, Y.V.; Jacobsen, S.E. Comprehensive analysis of silencing mutants reveals complex regulation of the Arabidopsis methylome. Cell 2013, 152, 352-364. [CrossRef] [PubMed]

39. Kumar, G.; Rattan, U.K.; Singh, A.K. Chilling-Mediated DNA Methylation Changes during Dormancy and Its Release Reveal the Importance of Epigenetic Regulation during Winter Dormancy in Apple (Malus x domestica Borkh.). PLoS ONE 2016, 11, e0149934. [CrossRef] [PubMed]

40. Pandey, G.; Sharma, N.; Sahu, P.P.; Prasad, M. Chromatin-Based Epigenetic Regulation of Plant Abiotic Stress Response. Curr. Gen. 2016, 17, 490-498. [CrossRef] [PubMed]

41. Asensi-Fabado, M.A.; Amtmann, A.; Perrella, G. Plant responses to abiotic stress: The chromatin context of transcriptional regulation. Biochim. Biophys. Acta 2017, 1860, 106-122. [CrossRef] [PubMed]

42. Annacondia, M.L.; Magerøy, M.H.; Martinez, G. Stress response regulation by epigenetic mechanisms: Changing of the guards. Physiol. Plant. 2018, 162, 239-250. [CrossRef] [PubMed]

43. Hershko, A.; Ciechanover, A. The ubiquitin system. Annu. Rev. Biochem. 1998, 67, 425-479. [CrossRef] [PubMed]

44. Kobayashi, M.; Oshima, S.; Maeyashiki, C.; Nibe, Y.; Otsubo, K.; Matsuzawa, Y.; Nemoto, Y.; Nagaishi, T.; Okamoto, R.; Tsuchiya, K.; et al. The ubiquitin hybrid gene UBA52 regulates ubiquitination of ribosome and sustains embryonic development. Sci. Rep. 2016, 6, 36780. [CrossRef] [PubMed] 
45. Hutchins, A.P.; Liu, S.; Diez, D.; Miranda-Saavedra, D. The repertoires of ubiquitinating and deubiquitinating enzymes in eukaryotic genomes. Mol. Biol. Evol. 2013, 30, 1172-1187. [CrossRef] [PubMed]

46. Nordhues, A.; Miller, S.M.; Muhlhaus, T.; Schroda, M. New insights into the roles of molecular chaperones in Chlamydomonas and Volvox. Int. Rev. Cell Mol. Biol. 2010, 285, 75-113. [PubMed]

47. Forreiter, C.; Kirschner, M.; Nover, L. Stable transformation of an Arabidopsis cell suspension culture with firefly luciferase providing a cellular system for analysis of chaperone activity in vivo. Plant Cell 1997, 9, 2171-2181. [CrossRef] [PubMed]

48. Lee, G.J.; Roseman, A.M.; Saibil, H.R.; Vierling, E. A small heat shock protein stably binds heat-denatured model substrates and can maintain a substrate in a folding-competent state. EMBO J. 1997, 16, 659-671. [CrossRef] [PubMed]

49. Löw, D.; Brändle, K.; Nover, L.; Forreiter, C. Cytosolic heat-stress proteins Hsp17.7 class I and Hsp17.3 class II of tomato act as molecular chaperones in vivo. Planta 2000, 211, 575-582. [CrossRef] [PubMed]

50. Noy-Meir, I. Desert Ecosystems: Environment and Producers. Annu. Rev. Ecol. Syst. 1973, 4, 25-51. [CrossRef]

51. Sala, O.E.; Lauenroth, W.K.; Parton, W.J.; Trlica, M.J. Water status of soil and vegetation in a shortgrass steppe. Oecologia 1981, 48, 327-331. [CrossRef] [PubMed]

52. Zhang, Y.Y.; Fischer, M.; Colot, V.; Bossdorf, O. Epigenetic variation creates potential for evolution of plant phenotypic plasticity. New Phytol. 2013, 19, 314-322. [CrossRef] [PubMed]

53. Salguero-Gómez, R.; Siewert, W.; Casper, B.B.; Tielbörger, K. A demographic approach to study effects of climate change in desert plants. Philos. Trans. R. Soc. Lond. B Biol. Sci. 2012, 367, 3100-3114. [CrossRef] [PubMed]

(C) 2018 by the authors. Licensee MDPI, Basel, Switzerland. This article is an open access article distributed under the terms and conditions of the Creative Commons Attribution (CC BY) license (http://creativecommons.org/licenses/by/4.0/). 